\title{
A specific mutation for Huntington's disease
}

Although only six months have passed since the isolation of the gene for Huntington's disease (HD) and the recognition of the mutation involved, there has already been an explosion of work on this subject, much of which is reported in the series of papers in this issue of Fournal of Medical Genetics. As the title of this review implies, most of the work relates to the properties of the HD mutation rather than to the nature and function of the gene itself.

The original HD Collaborative Research Group report ${ }^{1}$ gave details of the size of the gene, termed IT15, which has a cDNA of 10366 bases, and of the predicted protein (provisionally named huntingtin), estimated to contain 3144 amino acids with a molecular weight of $348 \mathrm{kDa}$. The amino acid sequence has shown no similarities with any known protein and there is no clear indication of its likely structure and function. Little further information has as yet emerged, either in publications or in presentations at the recent international workshop on HD. ${ }^{2}$ The gene contains 67 exons and shows universal expression in different body tissues, including neurones and glial cells, with no obvious differences in different regions of the brain. Thus the full impact of the discovery on our understanding of the neurobiology and pathology of the disease still lies in the future, though rapid progress can be anticipated.

By contrast, our understanding of the HD mutation and its relationship to the genetics and phenotype of the disorder has increased dramatically, in a manner comparable to that seen in myotonic dystrophy and fragile $\mathrm{X}$ mental retardation, also the result of trinucleotide repeat expansions, and each the subject of collections of papers in this journal one and two years ago respectively, ${ }^{34}$ soon after the mutations were identified. In the case of $\mathrm{HD}$, published and presented data on over 2000 HD chromosomes are now available (as well as on over 4000 normal chromosomes) and some broad conclusions are already possible; these are discussed fully in the subsequent papers and are summarised here.

First, the universal nature of the HD mutation deserves emphasis. In the initial paper, in three large series recently published together ${ }^{5-7}$ and in the series reported here, almost all HD patients studied, of widely differing origins, have shown the CAG expansion in the IT15 gene, as have most apparently isolated cases of HD. ${ }^{89}$ The small proportion not showing an abnormality have mostly proved to be misdiagnoses, or at least atypical, ${ }^{810}$ a situation closely comparable to that found in myotonic dystrophy ${ }^{11}$; in neither disease has a patient with a clearly defined different molecular basis yet been reported, though it is possible that such persons exist.

The initial finding of an inverse correlation between CAG repeat size and age at onset of HD has been conclusively confirmed by subsequent reports, both those already published ${ }^{5-7}$ and by the reports from The Netherlands, ${ }^{11}$ Scotland, ${ }^{12}$ and England ${ }^{13}$ in this issue. The different studies agree in finding the largest expansions and strongest age at onset correlation in the rare juvenile cases. By comparison with congenital myotonic dystrophy the expansions in this group are less extreme, rarely exceeding 100 repeats in juvenile $\mathrm{HD}$, but it is interesting that both disorders show a strong parent of origin effect, juvenile HD cases being mostly paternal in origin, while cases of congenital myotonic dystrophy are almost exclusively maternal. Outside these extreme groups, the age at onset correlation persists, and is indeed seen in the series of 133 HD patients with onset after 50 years reported here. ${ }^{1+}$ However, the range of onset for any given result appears to be too great to allow any specific conclusions in subjects seen for presymptomatic testing, ${ }^{\circ}$ though the finding of a small expansion in a relative at risk may suggest that a later onset is most likely. ${ }^{13}$

Somatic instability of the mutation has been a striking feature of the trinucleotide repeat mutations in both fragile $\mathrm{X}^{15}$ and myotonic dystrophy, ${ }^{1617}$ but data reported here ${ }^{18}$ show that this is not a major feature in HD, with close correspondence between the findings in blood and brain, and with no change in time between stored lymphoblasts and fresh blood. Similarly, identical twin pairs show similar repeat lengths, ${ }^{18}$ suggesting that most instability is prezygotic in origin. Two generation data are less frequent in HD than for the other disorders ${ }^{17}$ but confirm the previous observation of anticipation, especially in the male line, ${ }^{19}$ though the repeat sequence may decrease in size as well as expand. ${ }^{5}$ The important data on sperm given here ${ }^{18}$ not only confirm the prezygotic instability of the HD mutation, with a wide spread of repeat size contrasting with the constancy in somatic tissue; the results also show a larger average repeat size for sperm than for blood of the same subject, providing a valid basis for the anticipation.

Study of neurological diseases allied to HD has not shown presence of the HD mutation, 
apart from the single unusual family reported here ${ }^{20}$ that was previously reported as benign hereditary chorea. ${ }^{21}$ This should reassure clinicians that the generally accepted clinical and genetic classifications of HD and other neurodegenerative disorders are relatively robust, despite the difficulties in making a definitive diagnosis in some individual cases.

These rapid advances are understandably creating intense pressure for the clinical application of mutation testing in presymptomatic testing and in diagnosis; some of the difficult issues involved are discussed in this issue. ${ }^{22}$ It is likely that for presymptomatic testing, mutation analysis will rapidly supersede the use of linked markers, but it should be recognised that mutation testing is not without its own problems and potential errors. ${ }^{23}$ Several short reports on different and possibly improved approaches to analysis have already appeared ${ }^{24-26}$; one particularly important finding is that a CCG repeat sequence exists that is included in the original HD mutation assay and which shows variation in the normal population, though with a specific allele associated with HD. ${ }^{27}$ This variation could cause misinterpretation of a result at the borderline between the normal (10 to 35 repeats) and HD (over 36 repeats) ranges. It should be noted that one of the studies reported here ${ }^{10}$ has used a method that excludes this repeat and thus gives results around three repeats fewer than all other studies reported so far. Errors from sample misidentification ${ }^{2829}$ will remain as likely in mutation testing as with linked markers and may be more likely to give a definitively erroneous result, ${ }^{13}$ so the use of duplicate samples remains wise.

There is general agreement among all involved in HD presymptomatic testing that the full counselling and support protocols that have been evolved for testing with linked markers should not be abandoned or curtailed simply because laboratory aspects have become simpler. The previously published guidelines for predictive testing ${ }^{3031}$ are being revised but remain as important as ever. This issue contains two collaborative reports on testing by linked markers that show both the extent of testing across the world ${ }^{32}$ (over 1500 tests completed up to 1992) and also the complex ethical and social problems that arise even in the most carefully conducted series. ${ }^{33}$ Discussions at the recent World Federation of Neurology HD research group workshop and the associated meeting of the lay societies (International Huntington Association) showed that this was a topic of extreme concern, which will be closely monitored by consumers as well as by professionals. Those clinicians and laboratories who depart from the professionally accepted guidelines are likely to be putting themselves as well as their clients at risk.

Mutation testing will inevitably produce new dilemmas as well as simplifying presymptomatic prediction. The problem of the person at $25 \%$ prior risk requesting testing, where the healthy but at risk intervening parent could be shown to have the HD gene even if they were not to wish for testing themselves, is a particu- larly difficult situation, one that may still occur with the fullest counselling, but probably resolvable in most circumstances.

Finally, diagnostic use of HD mutation testing seems likely, given the specificity and sensitivity of the abnormality, to become part of regular neurological practice. This again will not be without its pitfalls, and will demand considerably more thought and explanation to those being tested than is usually the case in diagnostic medicine. Testing for HIV status is a not dissimilar situation where testing without full information is generally agreed to be unjustified. Not only will the patient (or if mentally impaired a close relative) need to be told the potential genetic implications of the test, but great care will be needed to avoid testing when an HD family member shows vague or atypical symptoms, since these could well be unrelated to HD even if the mutation were shown to be present, and the test would actually represent prediction not diagnosis.

The series of original papers, commentaries, and conference reports in this issue of fournal of Medical Genetics reflects the rapid progress and intense activity that currently characterise the field of Huntington's disease. The combination of excitement at the rapid progress being made, caution and concern that applications should be responsible and performed to the highest standards, together with longer term possibilities for understanding and therapy, have made 1993 a unique year for all those working on this devastating disorder.

PETER S HARPER

Institute of Medical Genetics,

University of Wales

College of Medicine,

Heath Park, Cardiff CF $4 X N$, UK.

1 The Huntington's Disease Collaborative Research Group A novel gene containing a trinucleotide repeat that is expanded and unstable on Huntington's disease chromosomes. Cell 1993;72:971-83.

2 MacMillan JC, Quinn N. Conference report. 7 Med Genet 1993;30:1039-41.

3 f Med Genet 1992;29:761-90.

4 7 Med Genet 1991;28:809-39.

5 Duyao M, Ambrose C, Myers R, et al. Trinucleotide repeat length instability and age of onset in Huntington's dislength instability and age of onset

6 Snell RG, MacMillan JC, Cheadle JP, et al. Relationship between trinucleotide repeat expansion and phenotypic variation in Huntington's disease. Nature Genet 1993;4:393-7.

7 Andrew SE, Goldberg YP, Kremer B, et al. The relationship between trinucleotide (CAG) repeat length and clinical features of Huntington's disease. Nature Gene 1993;4:398-403.

8 MacMillan JC, Snell RG, Tyler A, et al. Molecular analysis and clinical correlations of the Huntington's disease mutation. Lancet 1993;342:954-8.

9 Goldberg YP, Kremer B, Andrew SE, et al. Molecular analysis of new mutations causing Huntington disease. Nature Genet (in press).

10 Barron LH, Warner JP, Porteous M, et al. Study of the Huntington's disease associated trinucleotide repeat in the Scottish population. I Med Genet 1993;30:1003-7.

11 De Rooij KE, De Koning Gans PAM, Skraastad MI, et al. Dynamic mutation in Dutch Huntington's disease patients: increased paternal repeat instability extending to within the normal size range. $\mathcal{f}$ Med Genet 1993;30:9961002 .

12 Simpson SA, Davidson MJ, Barron L. Huntington's disease in Grampian region: correlation of the CAG repea number and the clinical features of the disease. $f \mathrm{Med}$ Genet 1993;30:1014-16.

13 Craufurd D, Dodge A. Mutation size and age at onset in Huntington's disease. F Med Genet 1993;30:1008-11

14 Kremer B, Squitieri FS, Telenuis H, et al. Molecula analysis of late onset Huntington's disease. $\mathcal{F}$ Med Genet 1993;30:991-5.

15 Oberle I, Rousseau F, Heitz D, et al. Instability of a 550 base pair DNA segment and abnormal methylation in fragile X syndrome. Science 1991;252:1097-102. 
16 Harley HG, Brook JD, Rundle SA, et al. Expansion of an unstable DNA region and phenotype variation in myotonic dystrophy. Nature 1992;355:545-6.

17 Buxton J, Shelbourne P, Davies J, et al. Detection of an unstable fragment of DNA specific to individuals with myotonic dystrophy. Nature 1992;355:547-8.

18 MacDonald ME, Barnes G, Srinidhi J, et al. Genetic but not somatic instability of CAG repeat length in Huntington's disease. 7 Med Genet 1993;30:982-6.

19 Ridley RM, Frith CD, Farrer LA, Conneally PM. Pattern of inheritance of the symptoms of Huntington's disease suggestive of an effect of genomic imprinting. $\mathcal{F} \mathrm{Med}$ Genet 1991;28:224-31.

20 MacMillan JC, Morrison NC, Nevin NC, et al. Identification of an expanded CAG repeat in the Huntington's disease gene (IT15) in a family reported to have benign hereditary chorea. 7 Med Genet 1993;30:1012-13.

21 Quarrell OWJ, Youngman S, Sarfarazi M, Harper PS. Absence of close linkage between benign hereditary chorea and the locus D4S10 (probe G8). F Med Genet 1988;25:191-4.

22 Simpson SA, Harding AE, on behalf of the United Kingdom Huntington's Disease Predictive Consortium. Predictive testing for Huntington's disease: after the gene. $f$ dictive testing for Huntingto

23 Harper PS. Clinical consequences of isolating the gene for Huntington's disease. BMF 1993;307:397-8.

24 Valdes JM, Tagle DA, Elmer LW, Collins FS. A simple non-radioactive method for diagnosis of Huntington' disease. Hum Mol Genet 1993;2:633-4.

25 Goldberg YP, Andrew SE, Clarke LA, Hayden MR. A PCR method for accurate assessment of trinucleotide repeat expansion in Huntington's disease. Hum Mol Genet 1993;2:635-6.

26 Riess D, Norremoelle A, Soerensen SA, Epplen JT. Improved PCR conditions for the stretch of (CAG)n repeats causing Huntington's disease. Hum Mol Genet repeats causin

27 Rubinstein DC, Barton DE, Ferguson-Smith MA. A trinucleotide repeat length polymorphism in the CCG rich regions of the Huntington gene. Linkage disequilibrium between the smallest allele and Huntington's disease chromosome. Hum Mol Genet (in press).

28 Lazarou LP, Meredith AL, Myring JM, et al. Huntington's disease: predictive testing and the molecular genetics laboratory. Clin Genet 1993;43:150-6.

29 Morrison PJ, Graham CA, Nevin NC. DNA storage and duplicate sampling: lessons learnt from testing for Hunt ington's disease. $\mathcal{F}$ Med Genet 1993;30:1042-3.

30 World Federation of Neurology Research Group on Huntington's Disease. Ethical issues policy statement on Huntington's disease molecular genetics predictive test. $f$ Med Genet 1990;27:34-8.

31 Craufurd D, Tyler A, on behalf of the UK Huntington's Predictive Consortium. Predictive testing for Huntington's disease: protocol of the UK Huntington's predicington's disease: protocol of the UK Huntingto

32 World Federation of Neurology Research Group on Huntington's Disease. Presymptomatic testing for Huntington's disease: a world wide survey. $\mathcal{F}$ Med Genet 1993;30:1020-2.

33 European Community Huntington's Disease Collaborative Study Group. Ethical and social issues in presymptomatic testing for Huntington's disease. $\mathcal{f}$ Med Genet 1993;30:1028-34.

Individual copies of this issue are available from the BMJ Bookshop, PO Box 295, London WC1H 9JR. Tel 071383 6244. Fax 071383 6662. Price $£ 14.50$. 